\title{
Lubrication Performance of Ionic Liquids as Lubricants for Space Mechanisms under High Vacuum and Low Temperature
}

\author{
Kenji Kobayashi $^{1)}$, Akihito Suzuki ${ }^{1)}$, Yukitoshi Fujinami ${ }^{2)}$, Takashi Nogi ${ }^{3)}$, Shingo Obara ${ }^{4)}$ and Masabumi Masuko ${ }^{1)^{*}}$ \\ ${ }^{1)}$ Department of Chemical Engineering, Graduate School of Science and Engineering, Tokyo Institute of Technology \\ S1-11, 2-12-1 Ookayama, Meguro-ku, Tokyo 152-8552, Japan \\ ${ }^{2)}$ Lubricants Research Laboratory, Idemitsu Kosan Co., Ltd. \\ 24-4 Anesakikaigan, Ichihara-shi, Chiba 299-0107, Japan \\ ${ }^{3)}$ Aerospace Research and Development Directorate, Japan Aerospace Exploration Agency \\ 7-44-1 Jindaiji Higashimachi, Chofu, Tokyo 182-8522, Japan \\ ${ }^{4)}$ Aerospace Research and Development Directorate, Japan Aerospace Exploration Agency \\ 2-1-1 Sengen, Tsukuba, Ibaraki 305-8505, Japan \\ *Corresponding author: mmasuko@chemeng.titech.ac.jp
}

( Manuscript received 18 April 2014; accepted 22 September 2014; published 15 April 2015 )

( Presented at Technical Session in the $5^{\text {th }}$ World Tribology Congress TORINO September 2013 )

\begin{abstract}
The objective of this study is to evaluate the boundary lubrication performance of ionic liquids under high vacuum and low temperature by taking the cosmic space environment into consideration, as a screening stage prior to evaluating lubrication performance in actual space mechanisms. The boundary lubrication performance of ionic liquids was evaluated at room temperature with a reciprocating linear motion tribometer, and at low temperature (from $-80^{\circ} \mathrm{C}$ to room temperature) with a unidirectional rotation tribometer. Low-temperature rheometry was also carried out. Ionic liquids showed a supercooling state and crystallization. This crystallization was prevented by mixing different ionic liquids together. The equimolar mixture of 1-ethyl-3-methyl-imidazolium bis(trifluoromethylsulfonyl) amide (EMI-TFSA), 1-butyl-3-methyl-imidazolium bis(trifluoromethylsulfonyl) amide (BMI-TFSA), and 1-hexyl-3-methyl-imidazolium bis(trifluoromethylsulfonyl) amide (HMI-TFSA) showed no crystallization in our experiment. The antiwear performance of this sample oil mixture was similar to that of MAC and much better than that of PFPE at low temperatures. This mixture prevented metal contact at $-80^{\circ} \mathrm{C}$, most likely due to its high viscosity and high adsorption of molecules.
\end{abstract}

Keywords: ionic liquids, space, high vacuum, low temperature, viscosity-temperature characteristics, wear, boundary lubrication

\section{Introduction}

There have been many studies on the performance of liquid lubricants for space mechanisms. Lubricants for space mechanisms are required to have very low vapor pressure, which is suitable under high-vacuum conditions in space. Therefore, only a few kinds of lubricants can be put to practical use in space mechanisms. Perfluoropolyether (PFPE) is one such lubricant, and many studies have already reported on its lubrication performance in space [1-5]. Multiplyalkylatedcyclopentane (MAC) is also a liquid lubricant used in space mechanisms, and its lubrication performance has also been studied thoroughly [6-8].

The operation of triboelements in space mechanisms is more demanding, since it requires more accurate and complex control. For example, the rotation speed and direction of the reaction wheel for posture control in an artificial satellite changes frequently with a small amount of liquid lubricants such as $50 \mathrm{mg}$ per bearing, in order to get low torque [9]. Currently, liquid lubricants for space mechanisms must function as not only elastohydrodynamic lubrication but also boundary lubrication for long periods and with only small amounts. Since PFPE decomposes in boundary lubrication [4], it is not suitable for the current mechanisms. In the case of MAC, since it is merely a hydrocarbon, the formulation of load-carrying additives is essential for use. However, there is not enough knowledge to select suitable additives that have very low vapor pressure. Therefore, in these circumstances, new liquid lubricants superior to PFPE and MAC are 
required.

Ionic liquid is salt in a liquid state. Ionic liquids have many unusual characteristics, such as negligible volatility, a wide temperature range, nonflammability, and excellent thermal stability. After Ye et al. showed the performance of ionic liquids as lubricants [10], a great number of reports on the lubrication performance of ionic liquids have been published. Among these reports, the application of ionic liquids as lubricants in space mechanisms, utilizing their very low vapor pressure, has also been studied [11-13].

Most previous studies evaluated the lubrication performance of ionic liquids at room temperature. However, since the temperature in a spacecraft is greatly influenced by sunlight radiation, the temperature changes approximately from $-120^{\circ} \mathrm{C}$ to $150^{\circ} \mathrm{C}$ in a satellite orbit [14]. Therefore, it is necessary to evaluate lubrication performance across a wide temperature range, especially at low temperature, as the tribology of ionic liquids at low temperature has not been well studied.

The objective of this study is to evaluate the boundary lubrication performance of ionic liquids under high vacuum and low temperature by taking the cosmic space environment into consideration, as a screening stage prior to evaluating lubrication performance in actual space mechanisms. In addition to the boundary lubrication performance, the low-temperature rheometry of sample oils was also investigated. Several kinds of ionic liquids, PFPE and MAC, were used for this study.

\section{Experimental}

\subsection{Sample lubricants}

The sample lubricants used in this study are shown in Table 1. They were 1-ethyl-3-methylimidazolium bis(trifluoromethylsulfonyl) amide (EMI-TFSA), 1-butyl-3-methylimidazolium bis(trifluoromethylsulfonyl) amide (BMI-TFSA), 1-hexyl-3-methyl-imidazolium bis(trifluoromethylsulfonyl) amide (HMI-TFSA), perfluoropolyether (PFPE), and multiply-alkylated cyclopentane (MAC). All ionic liquids, EMI-TFSA, BMI-TFSA, and HMI-TFSA were imidazolium-based ionic liquids with different alkyl chain lengths in a cation moiety, and had the same anion of TFSA.

\subsection{Vacuum tribometer}

The lubrication performance of sample oils under high vacuum was evaluated with two kinds of vacuum tribometers: a reciprocating linear motion tribometer and a unidirectional rotation tribometer. In both tribometers, the same set of test specimens that consisted of a ball (a precision bearing ball, dia. $3 / 8$ inch $(9.525 \mathrm{~mm})$, SUS440C stainless steel) and a flat disk (an end face of a cylindrical rod, $15.0 \mathrm{~mm}$ dia. and $15.0 \mathrm{~mm}$ length, SUS440C stainless steel) were used. In this study, the disk specimen was used as received without further polishing, and then this specimen was equivalent to the thick-oxide specimen reported previously $[15,16]$. The
Table 1 Test sample oils

\begin{tabular}{c|c}
\hline Sample name & 1-ethyl-3-methylimidazolium \\
bis(trifluoromethylsulfonyl) amide \\
(EMITFSA)
\end{tabular}

Table 2 Tribotest conditions

\begin{tabular}{|c|c|c|}
\hline \multicolumn{3}{|c|}{ Reciprocating linear motion tribometer } \\
\hline \multirow{7}{*}{$\begin{array}{c}\text { Load } \\
15 \mathrm{~N}\end{array}$} & Load & $15 \mathrm{~N}$ \\
\hline & $\begin{array}{l}\text { Reciprocating } \\
\text { frequency }\end{array}$ & $5 \mathrm{~Hz}$ \\
\hline & $\begin{array}{l}\text { Average sliding } \\
\text { speed }\end{array}$ & $50 \mathrm{~mm} / \mathrm{s}$ \\
\hline & Stroke length & $5 \mathrm{~mm}$ \\
\hline & \begin{tabular}{|l} 
Environmental \\
pressure
\end{tabular} & $<5 \times 10^{-4} \mathrm{~Pa}$ \\
\hline & Temperature & Room temperature \\
\hline & $\begin{array}{l}\text { Thickness of the } \\
\text { sample oil }\end{array}$ & $1-100 \mu \mathrm{m}$ \\
\hline \multicolumn{3}{|c|}{ Unidirectional rotation tribometer } \\
\hline \multirow{6}{*}{$\begin{array}{l}\text { Load } \\
100 \mathrm{~N}\end{array}$} & Load & $100 \mathrm{~N}$ \\
\hline & Sliding speed & $20.98 \mathrm{~mm} / \mathrm{s}$ \\
\hline & \begin{tabular}{|l} 
Total sliding \\
distance
\end{tabular} & $302 \mathrm{~m}$ \\
\hline & $\begin{array}{l}\text { Environmental } \\
\text { pressure }\end{array}$ & $<9.0 \times 10^{-5} \mathrm{~Pa}$ \\
\hline & Temperature & $\begin{array}{l}-80,-30,0^{\circ} \mathrm{C}, \\
\text { room temperature }\end{array}$ \\
\hline & Sample quantity & approx. $5 \mathrm{~g}$ \\
\hline
\end{tabular}

average surface roughness of the disk specimens was approximately $R a=15 \mathrm{~nm}$. Table 2 shows the tribotest conditions. The ball and disk specimens were washed with toluene by ultrasonic cleaning for $15 \mathrm{~min}$ followed by a UV/ozone cleaning before the tribotests. 
Two types of tribotests were carried out using the reciprocating linear motion tribometer: a lifetime test and a 48-hour test. For the lifetime tests, a small amount of sample oil was applied to the disk surface. The friction test terminated automatically when the friction force exceeded $4.5 \mathrm{~N}$. The total sliding distance until the termination of the test is expressed as a lifetime in this study. The 48-hour tests (total sliding distance: $8.64 \mathrm{~km}$ ) were carried out in order to measure the average friction coefficient and wear volume of the tested ball before the lifetime was over. In these tests, an oil film thickness of around $100 \mu \mathrm{m}$ was applied to avoid reaching the lifetime during the test. The experimental details were reported previously $[8,16]$.

Lubrication performance under high vacuum with temperatures ranging from $-80^{\circ} \mathrm{C}$, which was adjusted to the lower limit temperature of the rheometry, to room temperature was investigated with the unidirectional rotation tribometer. The disk specimen was installed in the oil cup that was mounted on a temperature-controlled stage consisting of a sheathed electric heater mounted on a cooling stage. Cooling was carried out by flowing liquid nitrogen inside the cooling stage, and an electric heater controlled the temperature precisely.

For both tribometers, the wear volume of the ball was calculated geometrically by the wear scar diameter, and was then subtracted by the volume calculated with the Hertzian contact diameter.

\subsection{Rheometer}

The viscosity-temperature characteristics of the sample oils at low temperature were measured with a rheometer (Anton Paar MCR-100) using a parallel-plate configuration (diameter of $50 \mathrm{~mm}$ and gap distance of 1 $\mathrm{mm}$ ) under a stress-controlled mode. Viscosity was measured continuously under a cooling mode from $25^{\circ} \mathrm{C}$ to $-78^{\circ} \mathrm{C}$ with a cooling rate of $5^{\circ} \mathrm{C} / \mathrm{min}$ followed by a heating mode from $-78^{\circ} \mathrm{C}$ to $25^{\circ} \mathrm{C}$ with the same rate of $5^{\circ} \mathrm{C} / \mathrm{min}$. The rotation speed was $37.7 \mathrm{rpm}(15.7$ $\mathrm{mm} / \mathrm{s}$ at the perimeter of the rotation plate) in the temperature range of $-50^{\circ} \mathrm{C}$ to $25^{\circ} \mathrm{C}$, and $0.377 \mathrm{rpm}$ $(0.16 \mathrm{~mm} / \mathrm{s})$ in the temperature range of $-78^{\circ} \mathrm{C}$ to $-50^{\circ} \mathrm{C}$.

\section{Results and Discussion}

\subsection{Low-temperature rheometry of sample oils}

Figure 1 shows the calculated viscosities of all the samples as a function of temperature under both cooling mode (Fig. 1(a)) and heating mode (Fig. 1(b)). Although most samples maintained fluidity and showed a monotonic change in viscosity with temperature, BMI-TFSA and HMI-TFSA showed drastically high values due to crystallization during the heating mode measurement.

The melting points of the ionic liquids used in this study are shown in Table 3 [17-20]. It has also been reported that the ionic liquids show supercooling

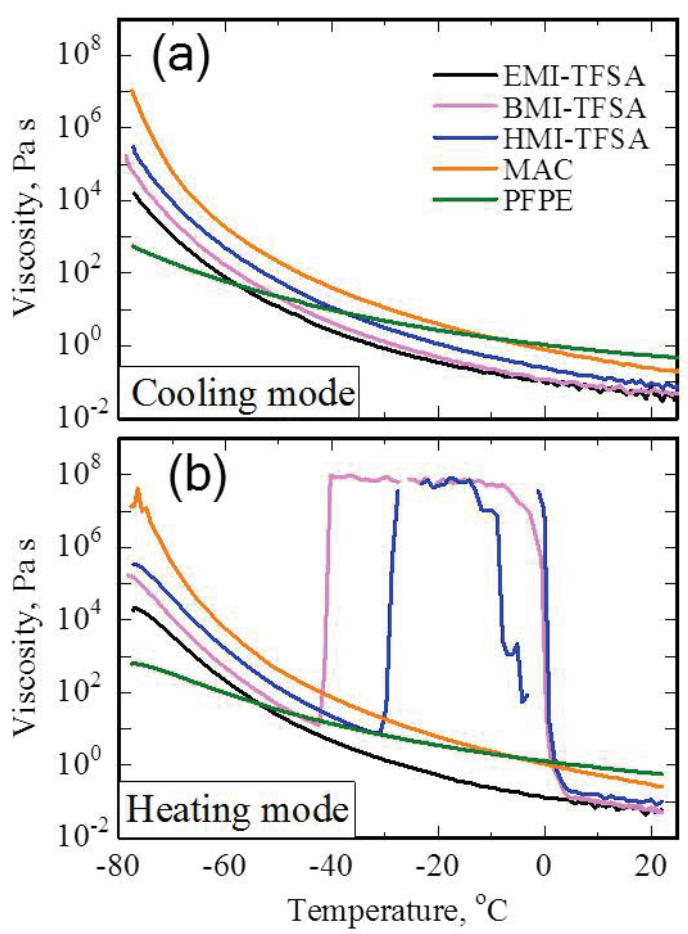

Fig. 1 Viscosities as a function of temperature under the cooling mode (a) and the heating mode (b)

phenomena and do not always show exact melting points [19,21]. Therefore, we considered that the drastic increase in viscosity in the heating mode measurement was due to the supercooling phenomena of these two ionic liquids. Even for EMI-TFSA, which did not crystallize in our measurement, the liquid state at low temperature was in the supercooling state and was at risk of solidification below the reported melting point temperature. This supercooling phenomenon was not observed for either MAC or PFPE.

In order to avoid the crystallization of ionic liquids, we tried to mix different ionic liquids with varying materials and concentrations. Table 4 lists the mixed ionic liquid samples. Figure 2 shows the results of the low-temperature rheometry. Figure 2(a) shows the results of the heating mode measurements for the mixed ionic liquids of MixILs 0 and MixILs 1 along with the neat ionic liquids of EMI-TFSA and HMI-TFSA. The crystallization of HMI-TFSA was effectively suppressed

Table 3 Melting points of ionic liquids

\begin{tabular}{c|c}
\hline Ionic liquid & Melting point $[\mathrm{K}]$ \\
\hline EMI-TFSA & $252.15^{* 1}$ \\
\hline BMI-TFSA & $264.15^{* 1,2}, 271.15^{* 3}$ \\
\hline HMI-TFSA & $266^{* 4}$ \\
\hline \multicolumn{2}{c}{ Reference ${ }^{* 1}:[17] ;^{* 2}:[18] ;^{* 3}:[19] ;^{* 4}:[20]$}
\end{tabular}


Table 4 Contents of mixed ionic liquids

\begin{tabular}{c|c|c}
\hline Name & Ionic liquid & $\begin{array}{c}\text { Mixing ratio, } \\
\mathrm{mol} \%\end{array}$ \\
\hline \multirow{2}{*}{ MixILs 0 } & EMI-TFSA & 10 \\
\hline \multirow{2}{*}{ MixILs 1 } & HMI-TFSA & 90 \\
\hline \multirow{2}{*}{ MixILs 2 } & EMI-TFSA & 25 \\
& HMI-TFSA & 75 \\
\hline \multirow{2}{*}{ MixILs 3 } & HMI-TFSA & 50 \\
\hline & EMI-TFSA & 33.3 \\
\hline
\end{tabular}

according to the increase in the concentration of EMI-TFSA, and the mixing of EMI-TFSA more than 25 mol $\%$ with HMI-TFSA entirely prevented the crystallization of HMI-TFSA. Figures 2(b) and 2(c) show the results of MixILs 2 (an equimolar mixture of BMI-TFSA and HMI-TFSA), and MixILs 3 (an equimolar mixture of three ionic liquids of EMI-TFSA, BMI-TFSA, and HMI-TFSA), respectively. Although both neat BMI-TFSA and HMI-TFSA were crystallized in the low-temperature rheometry (Fig. 1), the mixing of
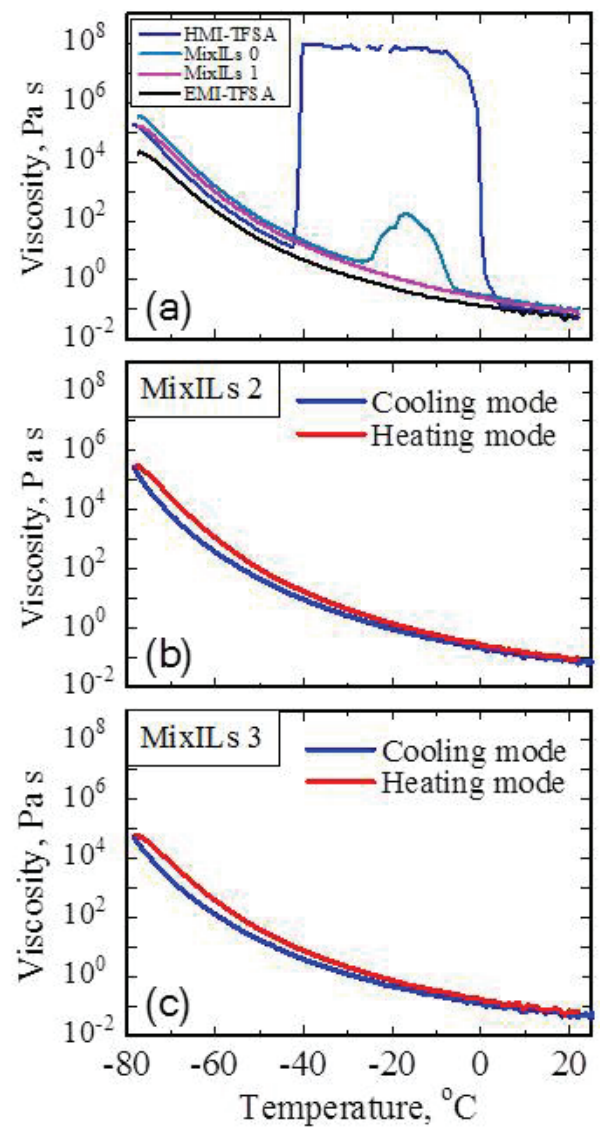

Fig. 2 Results of the low-temperature rheometry for mixtures of ionic liquids
Table 5 Density, ASTM slope $m$ and intercept $b$

\begin{tabular}{c|c|c|c}
\hline Sample & $\begin{array}{c}\text { Density, } \\
\mathrm{kg} / \mathrm{m}^{3}\end{array}$ & $m$ & $b$ \\
\hline EMI-TFSA & 1.512 & 3.87 & 9.71 \\
\hline MixILs 1 & 1.408 & 3.79 & 9.59 \\
\hline MixILs 2 & 1.412 & 3.80 & 9.61 \\
\hline MixILs 3 & 1.446 & 3.86 & 9.72 \\
\hline MAC & 0.850 & 3.38 & 8.71 \\
\hline PFPE & 1.850 & 2.00 & 5.33 \\
\hline
\end{tabular}

these ionic liquids effectively prevented crystallization. This kind of melting point depression by mixing ILs has already been reported [22].

The increase in heterogeneity resulting from the mixture of several kinds of ionic liquids with different alkyl chain lengths in cation moiety was helpful for disturbing the crystal alignment.

To study the temperature-viscosity characteristics of the samples, we applied the measured data obtained under the heating mode to a Walther-ASTM equation (Eq. (1)).

$$
\log (\log (v+0.7))=b-m \log T
$$

where, $v$ : kinetic viscosity, $\mathrm{m}^{2} / \mathrm{s}, T$ : temperature, $\mathrm{K}$.

Table 5 shows density data used to calculate kinematic viscosity for the lubricants that remained fluid in the heating mode. This table also shows the calculated values of slope $m$ and intercept $b$ in Eq. (1). The ionic liquids showed relatively high slope values, indicating poor temperature-viscosity. In addition, PFPE shows the lowest slope, indicating the best temperature-viscosity characteristic.

3.2. Lubrication performance at room temperature with the reciprocating linear motion tribometer

Figure 3 shows the results of the lifetime test, in which the lubrication lifetime is shown as a function of the oil film thickness initially supplied. Since we have already reported the results obtained with MAC $[8,16]$,

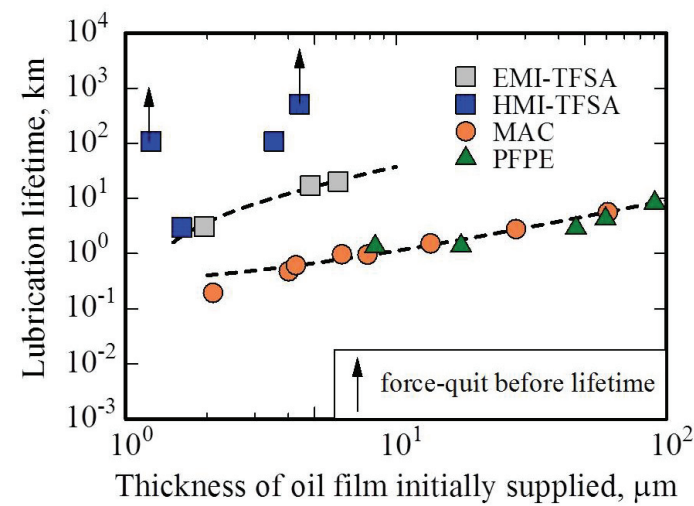

Fig. 3 Results of the lifetime test 


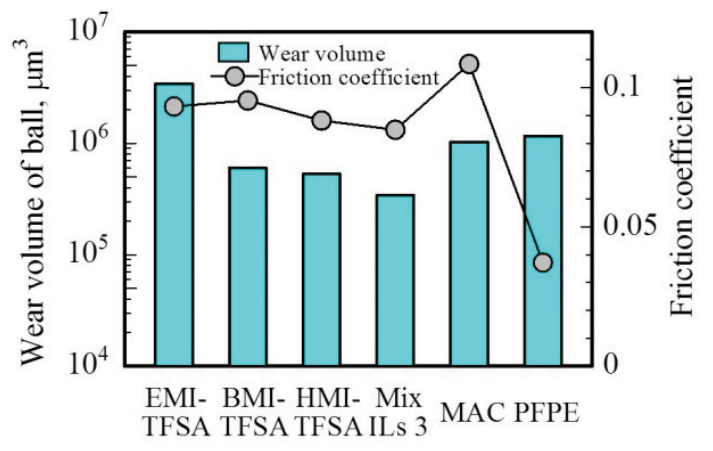

Fig. 4 Friction coefficients and wear volumes of steel balls in the 48 -hour test

the representative data for MAC are plotted in this figure. As the figure demonstrates, PFPE showed almost the same lubrication lifetime as MAC. Two ionic liquids, EMI-TFSA and HMI-TFSA, showed longer lifetimes than MAC and PFPE. Especially, HMI-TFSA showed a very long lifetime.

Figure 4 shows the average friction coefficients and wear volumes of steel balls in the 48-hour test. The notable results regarding friction were that MAC showed the highest and PFPE the lowest friction coefficients among all the lubricants tested, and all the ionic liquids had similar friction coefficients, which were intermediate between those of MAC and PFPE. In addition, the most notable result regarding wear was that EMI-TFSA showed the largest wear volume and that BMI-TFSA, HMI-TFSA, and MixILs 3 showed lower wear volumes than MAC and PFPE. Figure 5 shows the appearance of test disks after the tribotests

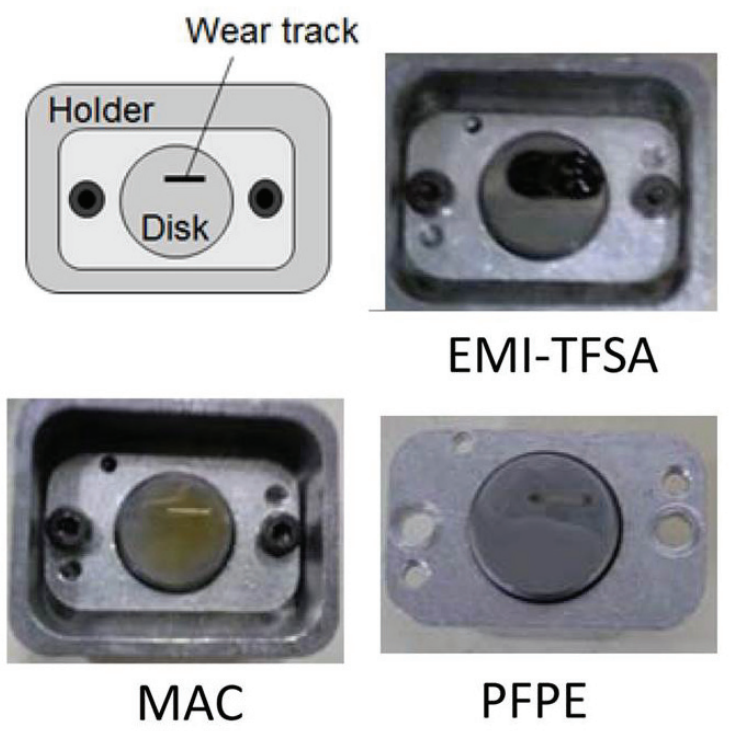

Fig. 5 Appearance of test disks after the 48-hour test with EMI-TFSA, PFPE, and MAC with EMI-TFSA, PFPE and MAC. As can be seen in this figure, EMI-TFSA showed black-colored deterioration after the test. We considered that this deterioration caused very large wear with EMI-TFSA. Neither BMI-TFSA nor HMI-TFSA showed this color change after the test.

3.3. Lubrication performance at low temperature with the unidirectional rotation tribometer

Lubricants that remained fluid in the measurement with low-temperature rheometry, i.e., EMI-TFSA; MixILs 1, 2, and 3; MAC, and PFPE, were evaluated for their lubrication performance at low temperature with the unidirectional rotation tribometer. Figure 6(a) shows the friction traces at $-80^{\circ} \mathrm{C}$, and Figure $6(\mathrm{~b})$ shows the data at room temperature as references except for MixILs 2. As shown in Fig. 6(b), MAC exhibited an abrupt increase in friction coefficient at the initial part of the test at room temperature, but the other oils showed rather smooth and low friction coefficients at room temperature. At $-80^{\circ} \mathrm{C}$, none of the oils tested showed an abrupt increase in the friction coefficient throughout the experiment. Figure 7 compares the friction coefficient (the averaged value of the friction data in the latter half of the tribotests) of EMI-TFSA, MixILs 1, MixILs 3, MAC and PFPE. As shown in Fig. 7 , all the samples showed higher friction coefficients at $-80^{\circ} \mathrm{C}$ than that at room temperature. Figure 8 shows wear scars on the steel balls after the tribotests at both room temperature and $-80^{\circ} \mathrm{C}$. At $-80^{\circ} \mathrm{C}$, EMI-TFSA

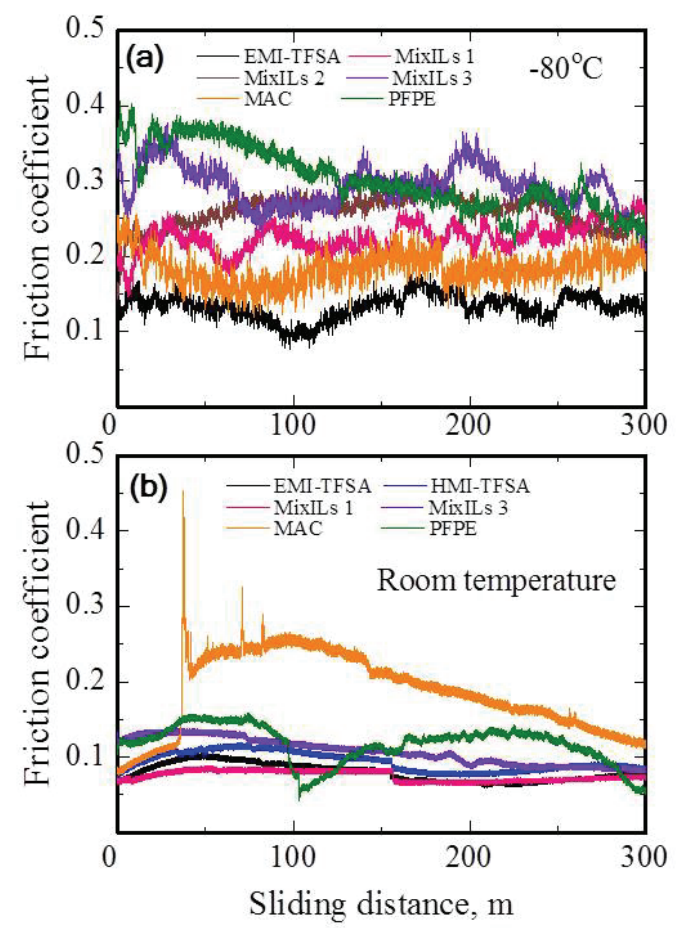

Fig. 6 Friction traces at $-80^{\circ} \mathrm{C}$ (a) and room temperature (b) 


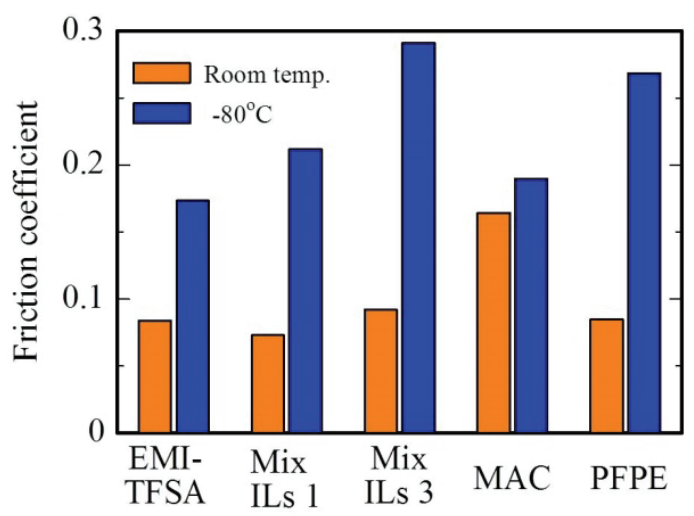

Fig. 7 Friction coefficients of EMI-TFSA, MixILs 1, MixILs 3, MAC, and PFPE at at $-80^{\circ} \mathrm{C}$ (a) and at room temperature (b)

and MixILs 2 and 3 showed almost no wear scars. This might be attributable to the high viscosity of lubricants at low temperature causing an almost full-film hydrodynamic lubrication state. However, as explain later, since some of the sample oils showed crystallization during the tribotest at $-80^{\circ} \mathrm{C}$, the phenomena are not simple and the reason for the absence of wear scar has not clarified in this stage of the study.

Figure 9 shows the appearance of the tested lubricants in the oil cup after the tribotest at $-80^{\circ} \mathrm{C}((\mathrm{a})$ MixILs 1; (b) MixILs 2; (c) MixILs 3). MixILs 1 crystallized (the white part at the center of the oil cup)
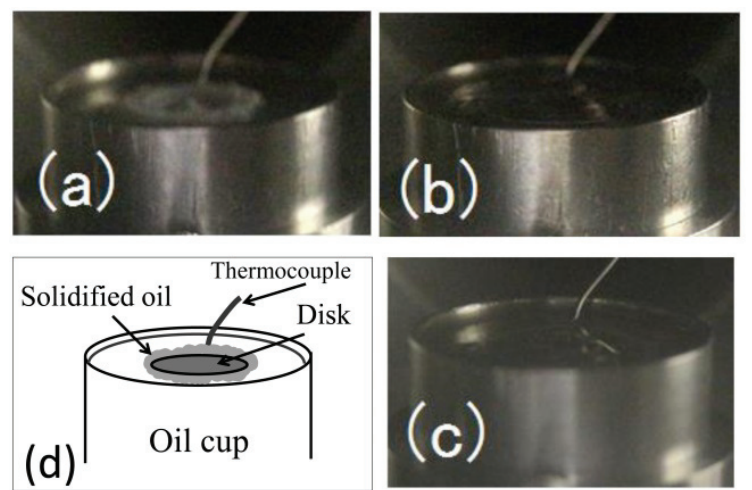

Fig. 9 Appearance of tested lubricants after the tribotest at $-80^{\circ} \mathrm{C}$ ((a) MixILs 1, (b) MixILs 2, (c) MixILs 3, (d) Schematic illustration of (a))

during the tribotest but did not crystallize in the low-temperature rheometry. It is not shown in Fig. 9 but was confirmed by visual observation, that EMI-TFSA crystallized during the tribotest. In contrast, neither MixILs 2 nor MixILs 3 crystallized during the tribotest. Although the reason why EMI-TFSA and MixILs 1 crystallized during the tribotest at low temperature but not in the low-temperature rheometry was not studied further, the presence of solid contacts had some role in triggering crystallization.

Figure 10 shows the friction coefficient (averaged in the latter half of the tribotests) and the wear volume of the steel balls after the tribotests with MixILs 3, MAC,

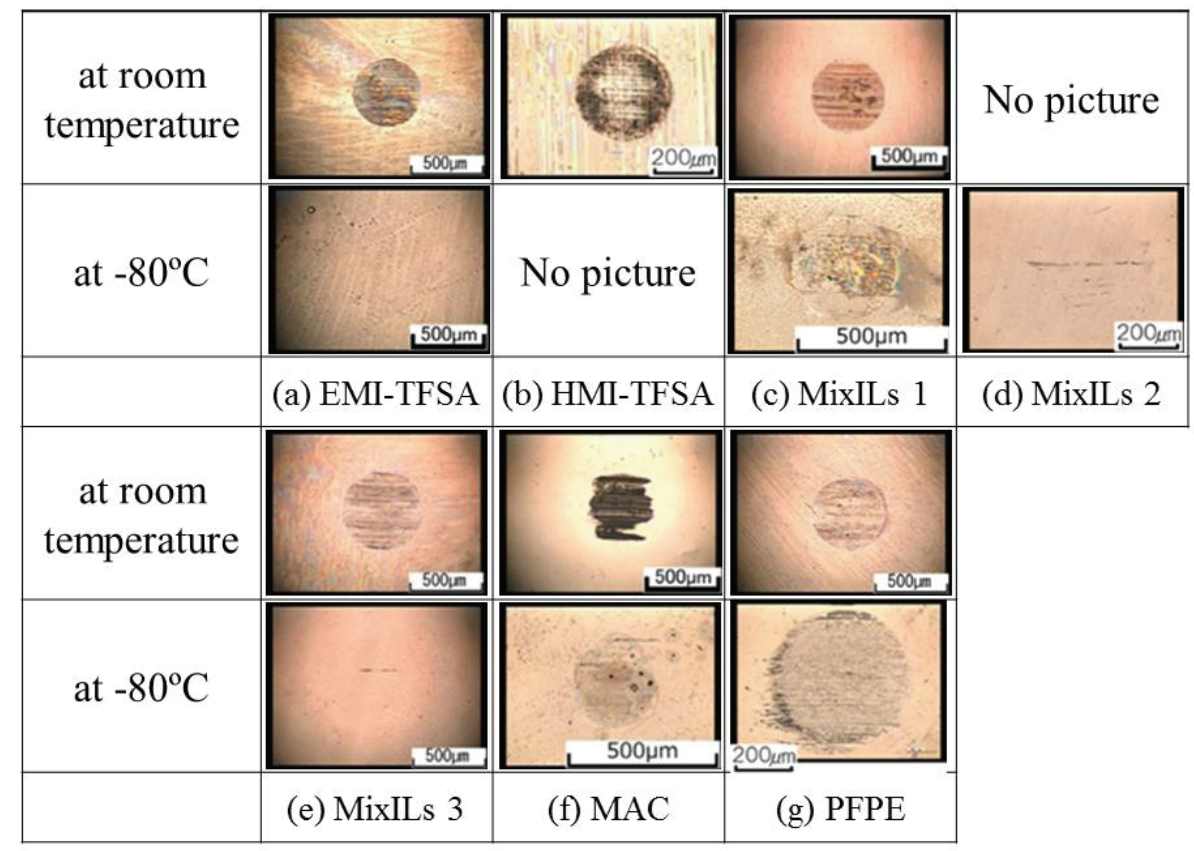

Fig. 8 Optical micrograph of wear scars on the ball after the wear tests 


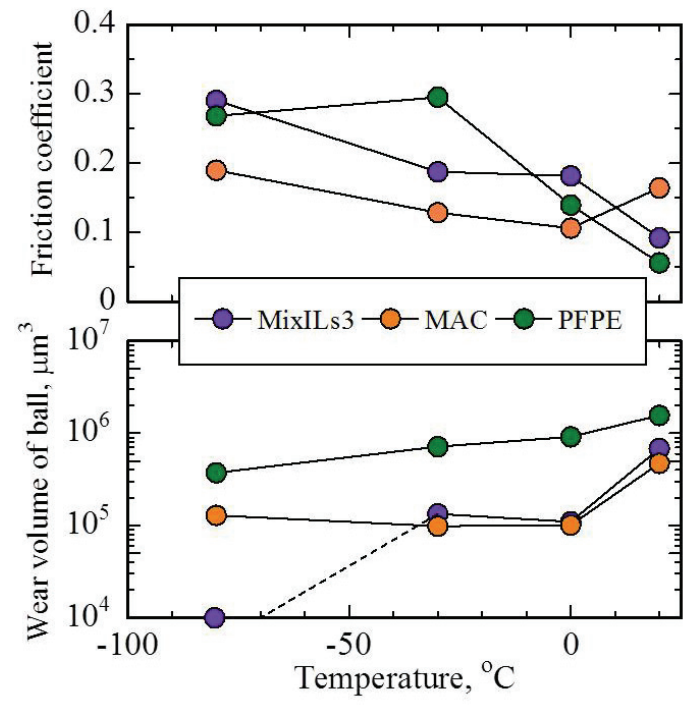

Fig. 10 Friction coefficients and wear volumes of steel balls after the tribotests at low temperatures with MixILs 3, MAC, and PFPE as a function of temperature

and PFPE as a function of temperature. MixILs 3 and PFPE tended to increase the friction coefficient and decrease the wear volume as the temperature decreased. The results shown in Fig. 10 are also displayed as a function of the viscosity of the sample oil at the testing temperature in Fig. 11. Figure 12 shows pictures of wear scars on both steel balls and disks after the tribotest.

Although a precise discussion is not possible at this stage of the study, the following can be pointed out. The friction coefficient increased and the wear on the ball decreased as the temperature decreased. No significant difference in wear between MAC and MixILs 3 was observed, whereas PFPE showed larger wear, which was probably caused by chemical wear brought about by the formation of metal fluoride. Although it has been known that TFSA-based ionic liquids also form metal fluoride, the extent of the chemical reaction was probably different, resulting in different degrees of wear. The most significant result was the wear with the MixILs 3 at $-80^{\circ} \mathrm{C}$. As shown in Fig. 12, almost no metallic contact occurred in this condition; this lack of contact was probably caused by the hydrodynamic lubrication state with high viscosity. However, taking into account that MAC showed metallic contact even at $-80^{\circ} \mathrm{C}$ where viscosity was much higher than that of MixILs 3, almost no surface damage are not able to be explained merely by the hydrodynamic lubrication with extremely high viscosity. A plausible cause is considered to be the adsorption of ionic liquid molecules to mitigate the contact severity in addition to the hydrodynamic action by the high viscosity of MixILs 3 at $-80^{\circ} \mathrm{C}$.

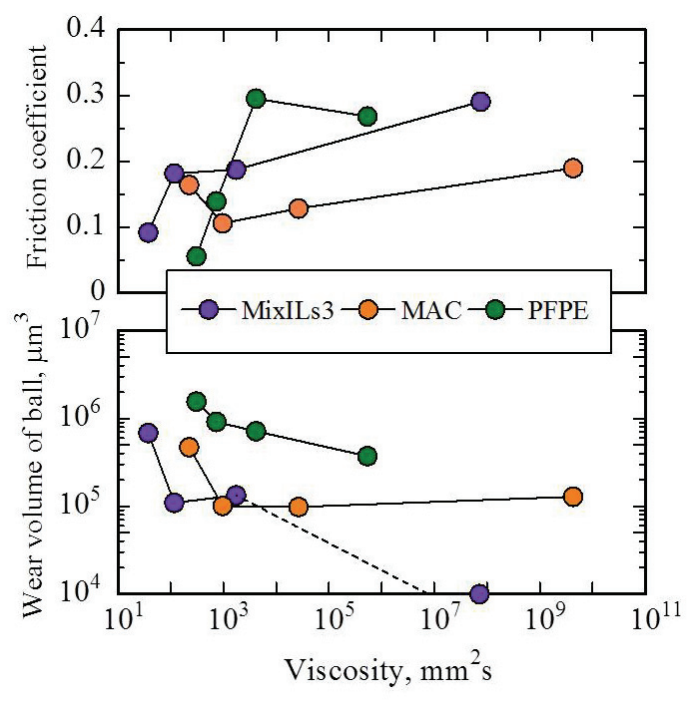

Fig. 11 Friction coefficients and wear volumes of steel balls after the tribotests at low temperatures with MixILs 3, MAC, and PFPE as a function of viscosity

\section{Conclusions}

The lubrication performance of imidazolium-based ionic liquids was evaluated under high vacuum at room temperature and at low temperature. The results were compared with those for PFPE and MAC, which have already been used for lubrication in the space environment. The following results were obtained.

- The lifetimes of the ionic liquids (EMI-TFSA and HMI-TFSA) at room temperature were longer than those of MAC and PFPE.

- The antiwear performance of BMI-TFSA and that of HMI-TFSA at room temperature in the 48-hour test were better than that of PFPE and that of MAC, but EMI-TFSA showed very large wear.

- BMI-TFSA and HMI-TFSA apparently showed a supercooling state and then crystallized. This was peculiar to the ionic liquids.

- Although mixtures of different kinds of ionic liquids suppressed crystallization, some of the ionic liquid mixtures that had not crystallized in rheometry might cause crystallization in the tribotest. Further study is necessary to obtain the optimum mix.

- All of the samples tested with the unidirectional rotation tribometer showed higher friction coefficients at $-80^{\circ} \mathrm{C}$ than at room temperature. MAC showed seizure-like high friction at room temperature but did not at low temperature.

- MixILs 3 showed no wear scar after the tribotest at $-80^{\circ} \mathrm{C}$. We attributed the absence of such a wear scar to not only the high viscosity of the liquid sample but also the adsorption of the ionic liquid molecules on the 


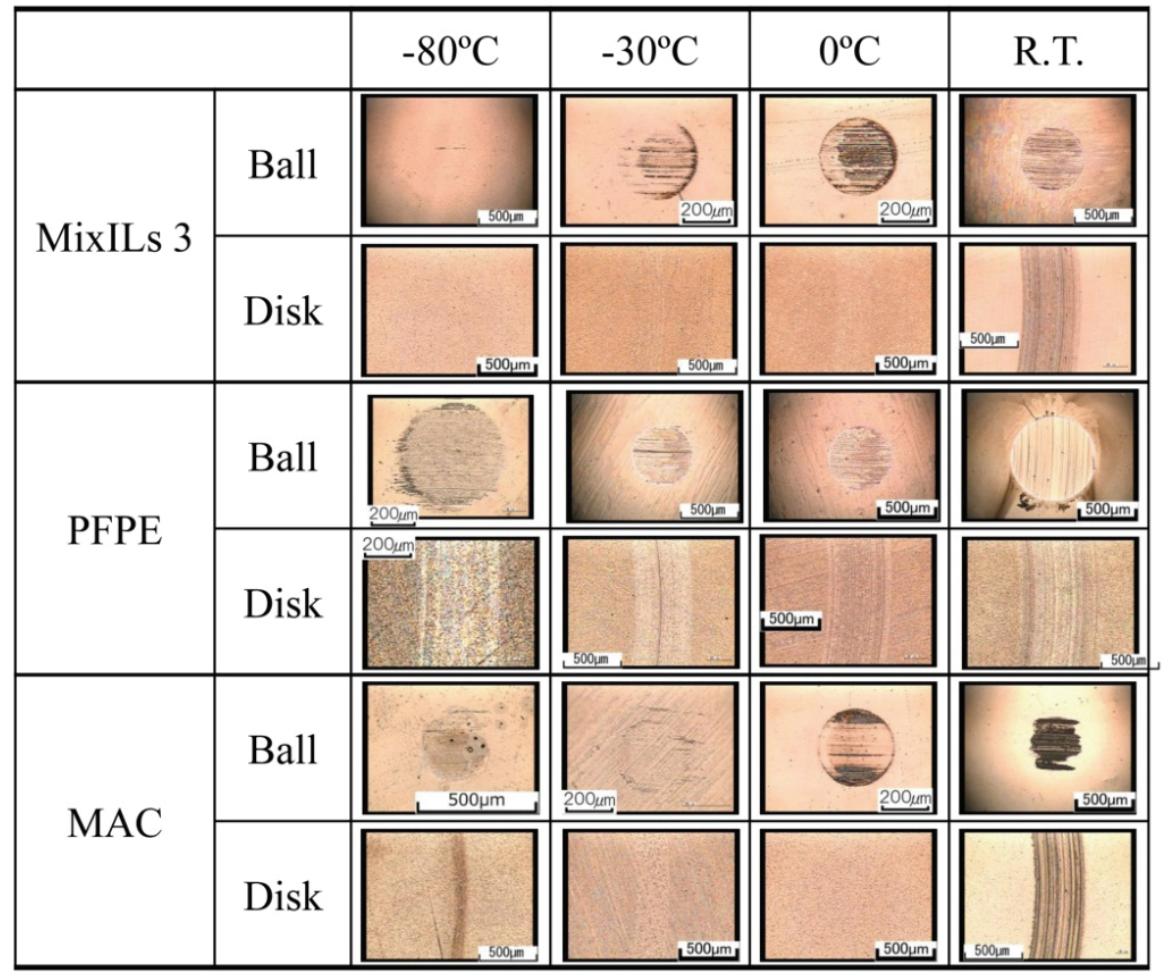

Fig. 12 Wear scars on both the steel balls and disks after the tribotest at low temperatures

surface.

\section{References}

[1] Mori, S. and Morales, W., "Reaction of Perfluoropolyethers (PFPE) with 440C Stainless Steel in Vacuum under Sliding Conditions at Room Temperature," NASA TP 2883, 1989, 1-9.

[2] Mori, S. and Morales, W., "Degradation and Crosslinking of Perfluoroalkyl Polyethers under X-ray Irradiation in Ultrahigh Vacuum," NASA TP 2910, 1989, 1-12.

[3] Masuko, M., Fujinami, I. and Okabe, H., "Lubrication Performance of Perfluoropolyalkylethers under High Vacuum," Wear, 159, 2, 1992, 249-256.

[4] Herrera-Fierro, P., Jones Jr., W. R. and Pepper, S. V., "Interfacial Chemistry of a Perfluoropolyether Lubricant Studied by X-ray Photoelectron Spectroscopy and Temperature Desorption Spectroscopy,” J. Vac. Sci. Technol. A 11, 2, 1993, 354-367.

[5] Jones, Jr., W, "Properties of Perfluoropolyethers for Space Applications, Tribol. Trans., 38, 3, 1995, 557-564.

[6] John, P. J., Cutler, J. N. and Sanders, J. H., "Tribological Behavior of a Multialkylated Cyclopentane Oil under Ultrahigh Vacuum Conditions," Tribol. Lett., 9, 3-4, 2001, 167-173.
[7] Braza, J., Jansen, M. J. and Jones, W. R., Jr., "Lubricated Bearing Lifetimes of a Multiply Alyklated Cyclopentane and a Linear Perfluoropolyether Fluid in Oscillatory Motion at Elevated Temperatures in Ultrahigh Vacuum," ESA SP, SP-653, August 2007, 12th European Space Mechanisms and Tribology Symposium (ESMATS).

[8] Masuko, M., Kishi, K., Suzuki, A. and Obara, S., "The Lifetime of Boundary Lubrication Performance of Small-Quantity-Applied Liquid Lubricants for Space Mechanisms Evaluated with a Vacuum Reciprocating Tribometer," Tribol. Trans., 53, 1, 2010, 75-83.

[9] Nosaka. M. and Obara. S., "Tribology in the H-II A Rocket and Satellites," J. Jpn. Soc. Tribologists, 51, 6, 2006, 419-425 (in Japanese).

[10] Ye, C., Liu, W., Chen, Y. and Yu, L., "Room-Temperature Ionic Liquids: a Novel Versatile Lubricant," Chem. Commun., 21, 2001, 2244-2245.

[11] Suzuki, A., Shinka, Y. and Masuko, M., "Tribological Characteristics of Imidazolium-Based Room Temperature Ionic Liquids under High Vacuum," Tribol. Lett., 27, 2007, 307-313.

[12] Street, K. W., Morales, W., Koch, V. R., Valco, D. J., Richard, R. M. and Hanks, N., "Evaluation of Vapor Pressure and Ultra-High Vacuum 
Tribological Properties of Ionic Liquids," Tribol. Trans., 54, 6, 2011, 911-919.

[13] Morales, W., Street Jr., K. W., Richard, R. M. and Valco, D. J., "Tribological Testing and Thermal Analysis of an Alkyl Sulfate Series of Ionic Liquids for Use as Aerospace Lubricants," Tribol. Trans., $55,6,2012,815-821$.

[14] Freeman, M. T., "Spacecraft On-Orbit Deployment Anomalies,” IEEE Aero. El. Sys. Mag., 8, 4, 1993, 3-15.

[15] Iijima, S., Masuko, M., Suzuki, A., Nogi, T. and Obara, S., "Effect of Oxide Layer of Metal Surface on Lubrication Performance of Liquid Lubricants in High Vacuum," J. Jan. Soc. Tribologists, 56, 5, 2011, 320-330 (in Japanese).

[16] Masuko, M., Iijima, S., Terawaki, T., Suzuki, A., Aoki, S., Nogi, T. and Obara, S., "Effect of Surface Oxide Layer of Steel on the Tribological Characteristics of Load-Bearing Additives for Multiply-Alkylated Cyclopentane Oil under High Vacuum," Tribol. Lett., 51, 1, 2013, 115-125.

[17] Dzyuda, S. V. and Bartsch, R. A., "Influence of Structural Variations in 1-Alkyl(aralkyl)-3Methylimidazolium Hexafluorophosphates and Bis(trifluoromethylsulfonyl)imides on Physical Properties of the Ionic Liquids," ChemPhysChem, 3, 2, 2002, 161-166.

[18] Bagno, A., Butts, C., Chiappe, C., D’Amico, F.,
Lord, J. C. D., Pieraccini, D. and Rastrelli, F., "The Effect of the Anion on the Physical Properties of Trihalide-Based N, N-Dialkylimidazoium Ionicl Iquids," Org. Biomol. Chem., 3, 9, 2005, 1624-1630.

[19] Fredlake, C. P., Crosthwaite, J. M., Hert, D. G., Aki, S. N. V. K. and Brennecke, J. F., "Thermophysical Properties of Imidazolium-Based Ionic Liquids," J. Chem. Eng. Data, 49, 4, 2004, 954-964.

[20] Crosthwaite, J. M., Muldoon, M. J., Dixon, J. K., Anderson, J. L. and Brennecke, J. F., "Phase Transition and Decomposition Temperatures, Heat Capacities and Viscosities of Pyridinium Ionic Liquids," J. Chem. Thermodynamics, 37, 6, 2005, 559-568.

[21] Nishikawa, K., Wang, S., Endo, T. and Tozaki, K., "Melting and Crystallization Behaviors of an Ionic Liquid, 1-Isopropyl-3-Methylimidazolium Bromide, Studied by Using Nanowatt-Stabilized Differential Scanning Calorimetry," Bull. Chem. Soc. Jpn., 82, 7, 2009, 806-812.

[22] Annat, G., Forsyth, M. and MacFarlane, D. R., "Ionic Liquid Mixtures-Variations in Physical Properties and Their Origins in Molecular Structure," J. Phys. Chem. B, 116, 28, 2012, 8251-8258. 